\title{
The Actuarial Model for Implicit Pension Debt of China
}

\author{
Meng Wang (Corresponding author) \\ Department of Science, Yanshan University, Qinhuangdao 066004, China \\ E-mail: wangmeng365@126.com \\ Yongmao Wang \\ Department of Science, Yanshan University, Qinhuangdao 066004, China
}

Yanhua $\mathrm{Su}$

Department of Humanities and Law, Yanshan University, Qinhuangdao 066004, China

The research is financed by Education Fund Project of Hebei Province. No. Z2008136

\begin{abstract}
Based on the basic principles of actuarial, with the latest provisions of pension system reform of china, using the individual cost method, implicit pension debt of China in 2009 can be calculated with the model.

Keywords: Old-age pension insurance, Implicit pension debt (IPD), Actuarial model

\section{Introduction}

\subsection{Background and status of implicit pension debt}

In view of the aging of the population increased and the elderly population rising trend, the State Council promulgated a national unity of the basic pension for urban workers program In 1997.In view of the faultiness of basic pension personal accounts of enterprises workers, unreasonable payment methods and the coverage which is not wide enough, in December 3, 2005 the State Council made the decision to improve the basic pension system of enterprises workers. Then some adjustment of the details is made. Because of these, the actuarial model of old-age pension insurance IPD of China in 2009 can be established base on the latest data from the latest requirements of china(Xian-fang $\mathrm{Lu}, 2000, \mathrm{p} 17-18)$.
\end{abstract}

\subsection{Related Concepts}

Implicit pension debt is the present value of accumulated funds that need to continue to be pay under the new system when PAYGO system was transformed into partial funding of pension system.

From the perspective of pension reform, urban workers can be divided into three categories: old-person who retired before the reform in 1997, middle-person who started to work before the reform and retire after the reform and new-person who started to work after the reform.

Middle-person started to work before 1997 and retired after 1997. Until 2009, some middle-persons have retired, most of them have not retired. So debt can be calculated base on old-person (age $x \geq 70$ ), middle-person who retired in 2009 (age between $58 \leq x \leq 69$ ) and middle-person who hold on a post (age between $32 \leq x \leq 57$ ). We assume that the average age of workers participating in the work is 20 years old. The average retirement age is 58 -year-old. The life span of workers is $w$ years old, and ${ }_{n} P_{m}$ stands for the probability of $m$ years old person survival to $m+n$ years old (Xiu-fang Li, 2000, p.398-403 )

\section{2 .The actuarial model of IPD for old-person}

Under the existing policy, retirement pension of old-person is based on the level of wage .In accordance with the ratio 
of the average growth rate of the community to carry out indexation adjustment (Xin-guang Lu,2004, p.47-48),We can deduce IPD of old-person in the year $t(t \geq 2009)$. As an example below in 2009, let us deduce IPD of old-person in 2009.

Proposition 1: For the year $\mathrm{t}$, that is $(t, t+1)$ year. The amount of $x(x \geq 70)$-years-old old-person is $N_{t, x}$. In 2009 the average level of pension of retired workers is $P_{2009}$. Growth rate of the average wage in society is $g$. Scheduled interest rate is $i$. Discount rate is $v=1 /(1+i)$. The social pension of every year is adjusted in accordance with the average wage growth indexation $a(0 \leq a \leq 1)$. The average retirement age is 58-years-old. So IPD of old-person in 2009 is,

$D_{1}=\sum_{x=70}^{w-1} N_{2009, x} Z_{x, 1}$

Among them $Z_{x, 1}=P_{2009} \sum_{k=1}^{w-1-x}(1+\alpha g)^{k}{ }_{k} P_{x} v^{k}$

Prove: By $\quad P_{2009}$ which is the average level of retired workers in 2009 and old-age pension in accordance with the social average wage growth rate $\mathrm{g}$ of the proportion $\alpha$ of index adjustment, the present value of pension that will be received in the future by $x$-years-old old-person in $2009 Z_{x, 1}$ is:

$$
P_{2009}(1+\alpha g) \cdot{ }_{1} P_{x} v+P_{2009}(1+\alpha g)^{2} \cdot{ }_{2} P_{x} v^{2}+, \quad P_{2009}(1+\alpha g)^{w-1-x} \cdot{ }_{w-1-x} P_{x} v^{w-1-x}=P_{2009} \sum_{k=1}^{w-1-x}(1+\alpha g)^{k}{ }_{k} P_{x} v^{k}
$$

So in early 2009 the present value of all $x$-year-old old-person of IPD is:

$N_{2009, x} \cdot Z_{x, 1}$

So in early 2009 the present value of all old-person of IPD is:

$D_{1}=\sum_{x=70}^{w-1} N_{2009, x} Z_{x, 1}$

\section{The actuarial model of IPD for the retired middle-person}

Proposition 2: For the year $t$, that is $(t, t+1)$ year. The amount of $x(58 \leq x \leq 69)$-years-old middle-person is $N_{t, x}$. In 2008 the average wage in society is $w_{2008}$. Growth rate of the average wage in society is $g$. Scheduled interest rate is $i$. Discount rate is $v=1 /(1+i)$.. The average retirement age is 58 -year-old. Transitional pension factor is $\beta$. The average age of starting to work is 20 -years-old. The average retirement age is 58 -years-old .So IPD of middle-person in 2009 is

$D_{2}=\sum_{x=58}^{69} N_{2009, x} \cdot B_{x, 2}+\sum_{x=58}^{69} N_{2009, x} \cdot A_{x, 2}$

Among them $A_{x, 2}=w_{2008} \cdot 1 \% \cdot(x-31) \sum_{k=1}^{w-1-x}(1+g)^{k}{ }_{k} P_{x} \cdot v^{k}$,

$B_{x, 2}=\beta(x-31) \cdot w_{2009-(x-57)} \cdot \sum_{k=1}^{w-1-x}{ }_{k} P_{X} \cdot v^{k}$

Prove: The pension of retired middle-person is constituted of basic pension, transitional pension and personal accounts constitute. For the purpose of calculating IPD of middle-person, we only need to calculate basic pension and transitional pension. According to the basic pension of enterprise workers approach to the implementation details, basic pension $=($ the average wage of last year before retirement + the average wage indexation $) \div 2 \times$ payment period $\times 1 \%$ (online, Jan 16,2006).

Because annual payment wage index of period which is regarded as payment period (period which is regarded as payment period is the years of work before social pooling is carried out) is calculated according to 1.0000 , when IPD is calculated , basic pension $=$ the average wage of last year before retirement $\times$ period which is regarded as payment period $\times 1 \%$. Period which is regarded as payment period of $x$-years-old middle-person $=38-[11-(x-58)]=x-31$.

So the actuarial present value in 2009 of basic pension that can be received by the retired middle-person when he is $x+1$ years old (in 2010) is:

$w_{2008}(1+g) \cdot(x-31) \cdot 1 \% \cdot_{1} P_{x} \cdot v$

The actuarial present value in 2009 of basic pension that can be received by the retired middle-person when he is 
$x+2$ years old (in 2011) is:

$w_{2008}(1+g)^{2} \cdot(x-31) \cdot 1 \%_{2} P_{x} \cdot v^{2}$

The actuarial present value in 2009 of basic pension that can be received by the retired middle-person when he is $w-1$ years old is:

$w_{2008}(1+g)^{w-1-x} \cdot(x-31) \cdot 1 \%^{\cdot}{ }_{w-1-x} P_{x} \cdot v^{w-1-x}$

So the overall actuarial present value in 2009 of basic pension that can be received by the $x$-years-old in 2009 retired middle-person is

$A_{x, 2}=w_{2008} \cdot 1 \% \cdot(x-31) \sum_{k=1}^{w-1-x}(1+g)^{k} \cdot{ }_{k} P_{x} \cdot v^{k}$

So all the IPD that is formed from the future basic pension of all retired middle-person is:

$\sum_{x=58}^{69} N_{2009, x} \cdot A_{x, 2}$

The formula of transitional pension of middle-person is:

Transitional pension $=$ payment calculation factor $\times$ period which is regarded as payment period $\times$ the average wage of last year before retirement (Fu-jie Sun, 2007, p.307). When $x$-years-old middle-person retired in 2009 the average wage in society of last year is $w_{2009-(x-57)}$.

So the actuarial present value in 2009 of transitional pension that can be received by the retired middle-person when he is $x$-years-old (in 2010) is:

$\beta(x-31) \cdot w_{2009-(x-57))}{ }_{1} P_{x} \cdot v$

The actuarial present value in 2009 of transitional that pension can be received by the retired middle-person when he is $x+1$-years -old (in 2011) is:

$\beta(x-31) \cdot w_{2009-(x-57)}{ }_{2} P_{x} \cdot v^{2}$

The actuarial present value in 2009 of transitional pension that can be received by the retired middle-person when he is $w-1$-years-old is:

$\beta(x-31) \cdot w_{2009-(x-57)}{ }^{\cdot}{ }^{w-1-x}{ }_{x} \cdot v^{w-1-x}$

So the overall actuarial present value in 2009 of transitional pension can be received by the $x(58 \leq x \leq 69)$-years-old in 2009 retired middle-person is

$B_{x, 2}=\beta(x-31) \cdot w_{2009-(x-57)} \cdot \sum_{k=1}^{w-1-x}{ }_{k} P_{x} \cdot v^{k}$

So all the IPD that is formed from the future transitional pension of all retired middle-person is:

$N_{2009, x} \cdot B_{x, 2}$

Base on the argument above, the IPD in 2009 of all retired middle-person is:

$D_{2}=\sum_{x=58}^{69} N_{2009, x} \cdot B_{x, 2}+\sum_{x=58}^{69} N_{2009, x} \cdot A_{x, 2}$

\section{4 .The actuarial model of IPD for middle-person holding a post}

Proposition 3: For the year $\mathrm{t}$, that is $(t, t+1)$ year. The amount of $x(32 \leq x \leq 57)$-years-old middle-person holding a post is $N_{t, x}$.In 2009 the average wage in society is $w_{2009}$. Growth rate of the average wage in society is $g$. Scheduled interest rate is $i$. Discount rate is $v=1 /(1+i)$. Transitional pension factor is $\beta$. The average age of starting to work is 20 -years-old. The average retirement age is 58 years old .So IPD of middle-person holding a post in 2009 is:

$D_{3}=\sum_{x=32}^{57} N_{2009, x} \cdot B_{x, 3}+\sum_{x=32}^{57} N_{2009, x} \cdot A_{x, 3}$

Among them $A_{x, 3}=w_{2009}(1+g)^{57-x} \cdot(x-31) \cdot 1 \% \cdot{ }_{58-x} P_{x} \cdot v^{58-x} \cdot \sum_{k=0}^{w-1-58}(1+g)^{k}{ }_{k} P_{58} \cdot v^{k}$ 
$B_{\mathrm{x}, 3}=\beta(x-31) w_{2009} \cdot(1+g)^{57-x} \cdot_{58-x} P_{x} \cdot v^{58-x} \sum_{k=0}^{w-1-58}{ }_{k} P_{58} \cdot v^{k}$

Prove: the actuarial present value of basic pension that will be received by the middle-person holding a post who is now $x(32 \leq x \leq 57)$ years old in 2009 in the year when middle-person holding a post is 58 years old after retirement is:

$w_{2009}(1+g)^{57-x}(x-31) \cdot 1 \%{ }_{58-x} P_{x} \cdot v^{58-x}$

The actuarial present value of basic pension in the year when middle-person holding a post retires is 59-years-old after retirement

$w_{2009}(1+g)^{57-x}(x-31) \cdot 1 \%{ }_{58-x} P_{x} \cdot v^{58-x} \cdot(1+g) \cdot{ }_{1} P_{58} \cdot v$

The actuarial present value of basic pension in the year when middle-person holding a post is $w-1$-years-old after retirement is:

$w_{2009}(1+g)^{57-x}(x-31) \cdot 1 \%{ }_{58-x} P_{x} \cdot v^{58-x}(1+g)^{w-1-58} \cdot{ }_{w-1-58} P_{58} \cdot v^{w-1-58}$

So the overall actuarial present value of basic pension that will be received by the middle-person holding a post who is now $x$-years-old in 2009 is:

$A_{x, 3}=w_{2009}(1+g)^{57-x} \cdot(x-31) \cdot 1 \%{ }_{58-x} P_{x} \cdot v^{58-x} \cdot \sum_{k=0}^{w-1-58}(1+g)^{k}{ }_{k} P_{58} \cdot v^{k}$

So all the IPD that is formed from the future basic pension of all middle-person holding a post is:

$\sum_{x=32}^{57} N_{2009, x} \cdot A_{x, 3}$

The below proof is similar to the proof of Proposition 2

All the IPD that is formed from the future transitional pension of all middle-person holding a post is :

$\sum_{x=32}^{57} N_{2009, x} \cdot B_{x, 3}$

Among them

$B_{\mathrm{x}, 3}=\beta(x-31) w_{2009} \cdot(1+g)^{57-x} \cdot_{58-x} P_{x} \cdot v^{58-x} \sum_{k=0}^{w-1-58}{ }_{k} P_{58} \cdot v^{k}$

Base on the argument above,

$D_{3}=\sum_{x=32}^{57} N_{2009, x} \cdot B_{x, 3}+\sum_{x=32}^{57} N_{2009, x} \cdot A_{x, 3}$

\section{Conclusion}

IPD is a complex project which need for economic development and population in accordance with the relevant parameters of the model combined with a comprehensive analysis of the actual situation. The model of this paper consider the latest system as detailed as possible, which has a strong practical interoperability and provides a quantitative basis for amendments to the system of government, as well as the implementation of related policies and measures.

\section{References}

Lu, Xianfang, \& Zeng, Qingwu. (2001). Life insurance actuarial mathematics.Tianjin,Nankai University publishing company.2001:17-18.

Li, Xiufang. (2000). Life Insurance Actuarial Practice. Tianjin,Nankai University publishing company2000:398-403.

Lu, Xinguang. (2004). The measure for IPD of basic pension. China Insurance Management University Journal. 2004 (6):47-48.

The decision of the State Council on enterprises to improve the basic pension system. [Online] Available: http://www.gdsi.gov.cn/upload/resource/sbdt_content.jsp?contentId=651 (Jan 16, 2006).

Sun, Fujie. (2007). Personal accounts pension actuarial model. Theoryl exploration. 2007(12):307. 